\title{
Impact of personality disorder comorbidity on cognitive-behavioral therapy outcome for mood and anxiety disorders: results from a university training clinic
}

\author{
Christopher B. Harte, ${ }^{1}$ Raymond C. Hawkins II ${ }^{2,3}$ \\ ${ }^{1}$ Harte Behavioral Health, Canton, MA; ${ }^{2}$ Fielding Graduate University, Santa Barbara, CA; ${ }^{3}$ The University of Texas at Austin, Austin, \\ TX, USA
}

\begin{abstract}
This study examined the impact of co-occurring personality disorder (PD) pathology on mood and anxiety symptom improvement in response to non-manualized, short-term, cognitive-behavioral therapy (CBT) delivered by trainees. The sample comprised 305 adult outpatients treated individually for mood (unipolar depression) and anxiety disorders [generalized anxiety disorder (GAD), panic disorder, social anxiety disorder (SAD), specific phobia, obsessive-compulsive disorder (OCD)] by doctoral students within a university training clinic. After comprehensive assessment of psychopathology, symptom-specific measures were administered at pre- and end-treatment. Both magnitude of disorder-specific mood and anxiety symptom change, as well as treatment outcome classification (via reliable

Correspondence: Raymond C. Hawkins II, The University of Texas at Austin, 108 East Dean Keeton Stop A8000, 78712 Austin, TX, USA.

Tel: +1.512.232.3354.

E-mail: rhawkins@utexas.edu

Contributions: $\mathrm{CBH}$ contributed to the conception and design of this study, performed the statistical analyses, interpreted the results, and drafted the paper. RCHII created and manages the clinical database from which the data were drawn, contributed to the conception and design and analysis of this study, the interpretation of the results, the verification of the accuracy of the findings, and the revision of this manuscript for publication. Both authors are accountable for the accuracy and integrity of this research project.

Conflict of interest: the authors declare no potential conflict of interest.

Note: portions of this study have been presented at the 2008 annual meeting of the Association for Behavioural and Cognitive Therachange and clinical significance indices) were utilized to assess treatment response. Results indicated that patients treated for depression, GAD, panic disorder, SAD, and specific phobias evidenced significant reductions in symptoms, irrespective of PD presence, and there was no interaction between PD comorbidity and level of symptom improvement. Among patients treated for OCD, PD pathology negatively impacted OCD symptom improvement. When treatment outcome was determined categorically, PD presence had a deleterious effect on clinical recovery only among patients treated for GAD. Neither the number of PD diagnoses nor PD cluster type moderated results. In conclusion, in most instances (with the exception of GAD and OCD patients), individuals with PDs treated by graduate student trainees within a university training clinic experienced significant mood and anxiety symptom improvement in response to short-term CBT, and these improvements were comparable to those without co-occurring PDs.
\end{abstract} pies, Orlando, FL; the 2008 annual meeting of the American Psychological Association, Boston, MA; and the 2008 Fielding Graduate University School of Psychology winter session, Santa Barbara, CA, USA.

Acknowledgments: the authors thank all graduate student clinicians who assessed and treated participants, as well as all clinical Psychology Faculty who supervised these cases. We also thank all participants who took part in this study.

Citation: Harte, C.B., \& Hawkins, R.C.II (2016). Impact of personality disorder comorbidity on cognitive-behavioral therapy outcome for mood and anxiety disorders: results from a university training clinic. Research in Psychotherapy: Psychopathology, Process and Outcome, 19(2), 124-135. doi: 10.4081/ripppo.2016.210

Received for publication: 29 February 2016.

Revision received: 8 July 2016.

Accepted for publication: 6 September 2016.

This work is licensed under a Creative Commons Attribution NonCommercial 4.0 License (CC BY-NC 4.0).

CCopyright C.B. Harte and R.C. Hawkins II, 2016

Licensee PAGEPress, Italy

Research in Psychotherapy:

Psychopathology, Process and Outcome 2016; 19:124-135

doi:10.4081/ripppo.2016.210
Key words: Personality disorder; Cognitive-behavioral therapy; Treatment outcome; Trainees.

\section{Introduction}

Co-occurring personality pathology is quite common among patients treated for mood and anxiety disorders, with prevalence rates varying between $30-60 \%$ (Friborg, Martinussen, Kaiser, Overgard, \& Rosenvinge, 2013; van Velzen \& Emmelkamp, 1996) and 30-40\% (Kelly, Nur, Tyrer, \& Casey, 2009; O'Leary \& Costello, 2001) for anxiety disorders and unipolar depression, respectively. The presence of comorbid personality disorders (PD) also has been found to increase the persistence of anxiety disorders (Skodol, Geier, Grant, \& Hasin, 2014). Given these high PD co-occurrence rates, and their contribution to the maintenance of anxiety and mood disorders, research has attempted to evaluate the impact of PD psychopathology on treatment outcome of other mental disorders. 
Initial reports (Reich \& Green, 1991; Reich \& Vasile, 1993; Shea et al., 1990; Shea, Widiger, \& Klein, 1992) concluded that personality pathology negatively affects treatment outcome of targeted mood and anxiety disorders. Similar results have been reported in more recent studies investigating the effects of concomitant PDs on the psychological and pharmacological treatment of depression (Grilo et al., 2005; Newton-Howes, Tyrer, \& Johnson, 2006). However, there have been several studies reporting opposing results. In fact, Dreessen and Arntz (1998) reviewed 35 studies assessing the influence of PDs on the treatment of anxiety disorders, and the authors concluded that it could not be determined with certainty whether PDs do in fact adversely impact treatment outcome. Weertman, Arntz, Schouten, and Dreesen (2005) did find a significant interaction between the presence of any PD and baseline anxiety symptom levels in predicting anxiety symptoms at the end of treatment; however, this was a small effect and the presence of PDs did not affect drop out rates. A review of the effects of PDs on the treatment of depression also reported generally inconsistent results (Mulder, 2002).

Although inconclusive, findings regarding the association between personality pathology and other mental disorder symptom improvement in response to cognitive-behavioral therapy (CBT) have primarily been conducted within the context of clinical trials with strict inclusion/exclusion criteria, and standardized manualized treatments. As such, little is known about the impact of cooccurring PDs on the delivery of CBT in general practice or in training clinics. To date, several studies have shown that the CBT is quite effective for mood and anxiety disorders when delivered in real-world clinical settings, with results comparable to many published randomized clinical trials (Gibbons et al., 2010; Persons, Roberts, Zalecki, \& Brechwald, 2006; Westbrook \& Kirk, 2005). Furthermore, CBT is effective in reducing mood and anxiety symptoms when delivered by trainees (e.g., pre-doctoral interns, postdoctoral fellows) in outpatient settings (Forand, Evans, Haglin, \& Fishman, 2011). To our knowledge, no studies have examined whether co-occurring PDs affect mood and anxiety symptom improvement in response to CBT delivered by trainees. This is particularly important, given that clinical trainees in psychology, social work, and medicine comprise a notable proportion of psychotherapy providers (Forand et al., 2011), and provide services that are often indistinguishable (in breadth, intensity, and with respect to treatment components) from experienced, licensed providers (Forand et al., 2011). Furthermore, the fact that the benefits of CBT can be produced by trainees with less training than experienced clinicians underscores the potential clinical, financial, and logistical utility of providing trainee services. Thus, it is an important goal to identify particular factors (such as personality pathology) that may predict treatment outcome in response to CBT delivered by trainees.
The purpose of the present study was to examine the effects of PD comorbidity on CBT treatment outcome for mood and anxiety disorders among adult outpatients treated by trainees within a university training clinic. To our knowledge, this is the first study to assess the influence of PD pathology on trainee-delivered CBT. The primary aim of this investigation was to explore whether presence of comorbid PD moderated the magnitude of symptom change among several mood and anxiety diagnostic groups, as well as whether PD comorbidity impacted treatment outcome classification (via reliable change and clinical significance indices). A secondary aim was to assess whether quantity and type of PD (i.e., PD cluster) affected treatment response. It was hypothesized that both patients with and without PD would show significant reductions in targeted mood and anxiety symptoms as a result of CBT treatment; however - given the inconsistency of previous studies examining the role of personality pathology on mood and anxiety disorders - it was uncertain whether there would be differential effects as a function of comorbid PD presence, quantity, or type.

\section{Materials and Methods}

\section{Participants and setting}

Participants treated for mood and anxiety disorders were selected from the practice research database of a clinical psychology training clinic (CPTC) of a university in the southwestern United States. The CPTC is an adult outpatient clinic housed within the psychology department and offers no cost psychological services to the community. The clinic is exclusively staffed by clinical psychology doctoral students, supervised by licensed clinical psychology faculty and staff, and specialized in CBT for mood and anxiety disorders. All patients receiving services within the clinic were referred by general practitioners or mental health professionals both within and outside of the university. The study received an exemption from the university institutional review board to use deidentified archival data for research purposes.

\section{Inclusion and exclusion criteria}

The current report comprised 305 outpatients treated by 99 graduate trainees, who were selected from a total sample of 481 individuals. One hundred forty-eight of the 481 individuals received psychological assessment only and were referred to other community clinicians for treatment (typical factors influencing out-of-clinic referral included: a patient's presenting problems were less appropriate for empirically supported treatments; timing of the initial assessments was such that there was insufficient opportunity for a full course of CBT; the student therapist's training needs were for assessment cases rather than treatment cases). The remaining 28 patients were treated with psychotherapy but not included in analysis for rea- 
sons stated below. Given the specialty nature of the clinic, only participants with a primary diagnostic and statistical manual of mental disorders-fourth edition (DSM-IV) (American Psychiatric Association, 1994) diagnosis of anxiety [generalized anxiety disorder (GAD), panic disorder - with and without agoraphobia, social anxiety disorder (SAD), specific phobia, obsessive-compulsive disorder (OCD) or unipolar depression (major depressive disorder, dysthymia)] were available for analyses. All other secondary and tertiary diagnoses were included. The primary diagnosis was defined as the structured clinical interview for DSM-IV axis I disorder (SCID-I) diagnosed mood or anXiety disorder that was causing the patient the most distress and/or most negatively affecting the patient's functioning, as determined by the client's subjective report, provided that a CBT empirically-supported treatment was available. Patients treated for other psychological disorders $(n=28)$ were not included in analyses, as there were not sufficient sample sizes to conduct between-group analyses of the association between personality pathology and treatment outcome [other disorders treated included the following: posttraumatic stress disorder $(\mathrm{n}=10)$, eating disorder $(\mathrm{n}=8)$, body dysmorphic disorder $(\mathrm{n}=1)$, impulse control disorder $(\mathrm{n}=2)$, pain disorder $(\mathrm{n}=1)$, adjustment disorder $(\mathrm{n}=1)$, alcohol abuse $(n=2)$, schizophrenia $(n=1)$, anger management difficulties $(n=2)]$. Other inclusion criteria of the study included: i) completion of pre-treatment disorderspecific measures; and ii) at least 18 years of age. Exclusion criteria were dictated by the general guidelines of the CPTC: i) presence of current psychotic features; ii) current suicidal or homicidal plan and/or intent; and iii) current alcohol or substance dependence.

\section{Intervention and procedure}

All individuals were first screened via telephone for appropriateness by the clinic director, or by a doctorallevel clinic manager. Those who were deemed to be in imminent danger to self or others, actively psychotic, or chemically dependent were referred elsewhere. Eligible patients were invited to the clinic for an initial assessment battery, which consisted of an unstructured 60-minute intake evaluation, a structured psychiatric interview to reliably establish differential diagnosis [structured clinical interview for the DSM-IV axis I diagnoses/patient version (SCID-I/P); First, Spitzer, Gibbon, \& Williams, 1996] and structured clinical interview for the DSM-IV axis II personality disorders (SCID-II; First, Gibbon, Spitzer, Williams, \& Benjamin, 1997), and completion of demographic and psychiatric symptom measures specific to an individual's primary diagnosis. As this was a clinical training setting, final diagnoses were made by agreement after discussion between the trainee interviewer and the supervising psychologist, considering the SCID-I, SCIDII, clinical diagnostic assessment interview, and domainspecific symptom measures, with relatively greater weight placed on the SCID-I interview.
If deemed appropriate for treatment, participants initiated individual CBT with the same clinician who conducted the assessment. Treatment consisted of approximately 12-16 sixty-minute weekly sessions, although duration of each session and length of overall treatment were tailored to the patients' needs. Psychotherapy treatment within the CPTC is tailored to the client's target problems; however, all treatment plans were based upon empirically-validated, disorder-specific, published CBT treatment protocols, as summarized by Barlow (2008) in the third and fourth editions of the Clinical handbook of psychological disorders: a step-by-step treatment manual, with adherence verified through weekly individual and group supervision. Anxiety treatments emphasized cognitive restructuring, diaphragmatic breathing and relaxation exercises, and graded exposures (with response prevention in the case of OCD). The depression intervention primarily entailed cognitive restructuring and behavioral activation. In addition to the above, all treatments incorporated psycho-education, weekly goal setting, skill-based home practice assignments and monitoring, and relapse prevention. At end-treatment, disorder-specific symptom measures were re-administered. Current psychiatric medication use was not recorded systematically in this CPTC database and therefore its potential effects on treatment outcome could not be statistically assessed. However, target problems were present at the start of treatment irrespective of concurrent psychotropic medication. Further, medication and dosages did not change during these brief psychological interventions (median of 12 sessions).

\section{Therapist training and oversight}

All assessments and treatment interventions were conducted by second-year clinical psychology doctoral students $(\mathrm{n}=99)$, who were closely supervised by licensed psychologists. All supervisors were affiliated to the Psychology Faculty of the University of Texas at Austin, Austin, TX, USA. Student clinicians received specialized training in both SCID administration and CBT interventions. Specifically, trainees received two 12-week courses (approximately $72 \mathrm{~h}$ ) in CBT entailing assessment (structured and unstructured clinical interviewing, psychometrics of disorder-specific measures), case conceptualization, techniques for particular mood and anxiety disorders, and research pertaining to treatment outcome for CBT for axis I and II disorders. Trainees carried an average caseload of 3-4 patients (seen weekly) and received intensive supervision ( $1 \mathrm{~h}$ of individual/week, $1.5 \mathrm{~h}$ of group/ week). All cases were both video- and audio-recorded for training purposes; these recordings were reviewed weekly by clinical supervisors, with trainees receiving feedback on a weekly basis. All licensed supervisors within the CPTC were doctoral-level experts in CBT, and each had on average 25 years of experience supervising trainees in CBT. 


\section{Outcome measures}

\section{Beck depression inventory-II}

Symptoms of depression were assessed using the Beck depression inventory-II (BDI-II) (Beck, Steer, \& Brown, 1996), which is a 21-item self-report instrument used extensively in research and treatment outcome studies. Total scores range from 0 to 63 with higher scores indicating increased levels of depression severity. The BDI-II has demonstrated excellent test-retest reliability and good validity (Beck et al., 1996).

\section{Penn state worry questionnaire}

Symptoms of GAD were assessed with the Penn state worry questionnaire (PSWQ) (Meyer, Miller, Metzger, \& Borkovec, 1990), which includes 16 items that capture the generality, excessiveness, and uncontrollability of pathological worry. Total scores range from 16 to 80 with higher scores indicating increasing severity of pathological worry. The instrument has demonstrated good internal consistency and good test-retest reliability (Beck, Stanley, \& Zebb, 1995; Meyer et al., 1990).

\section{Panic appraisal inventory}

Severity of panic was measured with the revised version of the panic appraisal inventory (PAI; Telch, Brouillard, Telch, Agras, \& Taylor, 1989). The PAI is a 45-item self-report scale that evaluates three dimensions of panic-related threat appraisals: anticipated panic (PAI1), panic consequences (PAI-2), and panic coping (PAI3). All 15 items within each scale are averaged separately to form total scores. For the purposes of this study, the PAI-1 was used as the primary subscale to determine treatment outcome. This subscale was selected because it has shown to be the strongest predictor of both short- and long-term improvement in clinical status (Cho, Smits, Powers, \& Telch, 2007). The PAI has demonstrated excellent psychometric properties (Feske \& De Beurs, 1997; Telch et al., 1989).

\section{Appraisal of social concerns scale}

Social anxiety symptomatology was assessed with the appraisal of social concerns scale (ASC; Telch et al., 2004). The ASC is a 20-item self-report instrument that assesses specific threat appraisals relevant to social anxiety such as fear of negative evaluation from others, visibility of anxiety symptoms, and social helplessness. A total score is derived by taking the mean of all items (total score range 0-100). The ASC has demonstrated good internal consistency, test-retest reliability, and validity (Schultz et al., 2006; Telch et al., 2004). The ASC has been shown to be sensitive to treatment effects (Lucas \& Telch, 1993), comparing favourably with other clinical status measures of social anxiety (Telch et al., 2004).

\section{Yale-Brown obsessive-compulsive scale}

Levels of obsessive-compulsive symptoms were assessed with the severity scale of the Yale-Brown obsessive-compulsive scale (Y-BOCS; Goodman, Price, Rasmussen, Mazure, Delgado, et al., 1989; Goodman, Price, Rasmussen, Mazure, Fleischmann, et al., 1989), which is a 10 -item instrument that evaluates both obsessions (5 items) and compulsions (5 items). Total scores range from 0 to 40 . The Y-BOCS has demonstrated satisfactory reliability and validity (Goodman, Price, Rasmussen, Mazure, Delgado, et al., 1989; Goodman, Price, Rasmussen, Mazure, Fleischmann, et al., 1989).

\section{Beck anxiety inventory}

Given the heterogeneous nature of specific phobia presentations (i.e., subtypes) and consequential wide array of subtype-specific measures, no uniformity exists as to one gold-standard phobia assessment measure. As such, the Beck anxiety inventory (BAI; Beck, Epstein, Brown, \& Steer, 1988) was used as a proxy for anxiety symptomatology. The BAI is a 21-item self-report instrument (score range 0-63) shown to have good psychometric properties (Beck \& Steer, 1990).

\section{Statistical analysis}

Differences in baseline characteristics [treated patients $v s$ those who were referred elsewhere after initial assessment, treated patients with vs without comorbid PD, completers $v s$ dropouts (those completing less than five sessions)] were examined with $t$-tests or Pearson $\chi^{2}$ tests, as appropriate. Multivariate analyses were conducted on an intent-to-treat basis using full information maximum likelihood (FIML) estimation (Little \& Rubin, 2002). Missing values for the six outcome measures were estimated using baseline diagnostic characteristics (number of axis I and axis II diagnoses, primary disorder treated), number of treatment sessions, as well as each respective pre-treatment primary outcome score. General linear modelling (in the form of $2 \times 2$ repeated measures ANCOVA models) was used as the primary analytic approach to examine magnitude of symptom reduction between those with and without comorbid personality pathology at each time point (pre- and end-treatment) within each diagnostic group. Planned comparison $F$-tests for adjusted cell means were used to assess between-group differences in cases where the overall interaction term was statistically significant. Age, number of axis I diagnoses, and number of treatment sessions were entered as covariates in all analyses. A series of hierarchical linear regression analyses were employed to examine the associations between both quantity (i.e., number of PD diagnoses) and type of PD pathology (i.e., PD cluster) and symptom change for each axis I diagnostic group. In these analyses, the above covariates, with the addition of pre-treatment severity scores, were entered in step 1 of the models, and number of axis II diagnoses or cluster A, cluster B, cluster $\mathrm{C}$, or PD not otherwise 
specified (NOS) presence (binarily coded as yes/no), were entered in step 2 of the models.

Clinically significant change was also calculated for all individuals using a reliable change index (RCI; Jacobson \& Truax, 1991) and by using outcome measure-specific a priori cut-off scores shown to empirically distinguish between diagnostic cases and non-cases. RCI was as follows:

$$
\left[\left(x_{2-} x_{1}\right) / \mathrm{S}_{\mathrm{diff}}\right]
$$

where $x_{1}$ is pretest score and $x_{2}$ is posttest score; $\mathrm{S}_{\mathrm{diff}=} \sqrt{ }\left[2\left(\mathrm{~S}_{\mathrm{E}}\right)^{2}\right]$, and $\mathrm{S}_{\mathrm{E}}=\mathrm{S}_{1} \sqrt{ }\left(1-r_{\mathrm{xx}}\right)$, where $\mathrm{s}_{1}$ is the standard deviation of the control group, and $r_{\mathrm{xx}}$ is the test-retest reliability of the measure. An RCI of 1.96 is generally considered reliable.

Patients were categorized as recovered if they displayed reliable change (in the direction of lower symptom scores) and fell below the pre-determined cut-off scores. Associations between PD presence and treatment response (recovered, non-recovered) were examined within each diagnostic group via hierarchical logistic regression. In each model, the above covariates and pre-treatment severity score were entered in step 1 of the model, and presence of Axis II pathology was entered in step 2 of the models. Adjusted odds ratios (ORs) with their 95\% confidence intervals (CIs) were calculated.

Alphas for all analyses were Bonferroni corrected to account for the fact that separate models were run for each of the six diagnostic groups $(.05 / 6=.008)$. All analyses were performed using SPSS statistical software version 19.0 (SPSS Inc., Chicago, IL, USA).

\section{Results}

\section{Pre-treatment participant characteristics}

The majority of the sample (77\%) was diagnosed with a comorbid axis I disorder, and approximately $37 \%$ of the study sample had a co-occurring personality disorder (axis II) diagnosis (Table 1). Among those with axis II comorbidity, the average number of axis II diagnoses was 1.5 [standard deviation $(\mathrm{SD})=.64$; range $=1-3]$. The proportion of patients with axis II disorders across the six diagnostic subgroups is

Table 1. Demographic, diagnostic, and treatment characteristics of individuals with and without clinically diagnosed axis II psychopathology $(\mathbf{n}=\mathbf{3 0 5})$.

\begin{tabular}{|c|c|c|c|c|c|}
\hline \multirow[t]{2}{*}{ Characteristics } & \multicolumn{2}{|c|}{ Absence of PD $(n=191)$} & \multicolumn{2}{|c|}{ Presence of PD $(n=114)$} & \multirow[t]{2}{*}{$\mathbf{E S}^{\circ}$} \\
\hline & M (SD) & n $(\%)$ & M (SD) & n $(\%)$ & \\
\hline Age (years) & $31.6(10.46)$ & - & $32.5(10.12)$ & - & .09 \\
\hline Education (years) & $15.4(2.23)$ & - & $15.0(2.01)$ & - & .18 \\
\hline \multicolumn{6}{|l|}{ Gender } \\
\hline Male & - & $73(38.2)$ & - & $51(44.7)$ & .06 \\
\hline Female & - & $118(61.8)$ & - & $63(55.3)$ & \\
\hline \multicolumn{6}{|l|}{ Ethnicity } \\
\hline White/Caucasian & - & $146(76.4)$ & $91(79.8)$ & - & .11 \\
\hline Black/African-American & - & $4(2.1)$ & $2(1.8)$ & - & \\
\hline Latino & - & $33(17.3)$ & $16(14.0)$ & - & \\
\hline Asian & & $7(3.7)$ & $2(1.8)$ & - & \\
\hline Other & - & $1(0.5)$ & $3(2.6)$ & - & \\
\hline \multicolumn{6}{|l|}{ Employed } \\
\hline Yes & - & $172(91.0)$ & - & $104(91.2)$ & .004 \\
\hline No & - & $17(9.0)$ & - & $10(8.8)$ & \\
\hline \multicolumn{6}{|l|}{ Marital status } \\
\hline Single & - & $107(56.0)$ & - & $72(63.2)$ & .13 \\
\hline Married & - & $66(34.6)$ & - & $26(22.8)$ & \\
\hline Divorced & - & $18(9.4)$ & - & $16(14.0)$ & \\
\hline Axis I diagnoses ${ }^{\#}$ & $2.4(1.38)$ & - & $3.2(1.63)$ & - & $.52 * * *$ \\
\hline \multicolumn{6}{|l|}{ Primary axis I disorder treated } \\
\hline Unipolar depression ${ }^{\S}$ & - & $32(16.8)$ & - & $28(24.6)$ & .19 \\
\hline GAD & - & $22(11.5)$ & - & $17(14.9)$ & \\
\hline Panic disorder & - & $53(27.7)$ & - & $22(19.3)$ & \\
\hline SAD & - & $50(26.2)$ & - & $38(33.3)$ & \\
\hline OCD & - & $20(10.5)$ & - & $4(3.5)$ & \\
\hline Specific phobia & - & $14(7.3)$ & - & $5(4.4)$ & \\
\hline Treatment sessions & $14.4(8.59)$ & - & $13.0(8.25)$ & - & .16 \\
\hline
\end{tabular}

$\mathrm{PD}$, personality disorder; $\mathrm{ES}$, effect size; $\mathrm{M}$, mean; $\mathrm{SD}$, standard deviation; $\mathrm{GAD}$, generalized anxiety disorder; $\mathrm{SAD}$, social anxiety disorder; OCD, obsessive-compulsive disorder. *** $<.001$. Axes I and II psychopathology were assessed via the structured clinical interview axes I and II (SCID-I and SCID-II) for the diagnostic and statistical manual of mental disorders-fourth edition (DSM-IV). ${ }^{\circ}$ Effect sizes in Cohen's $d$ for all variables with the exception of gender, employment, marital status, and primary axis I disorder treated, which are reported as Cramer's $\phi .{ }^{\#}$ Comorbid axis I disorders (other than the six primary disorders treated) were post-traumatic stress disorder, anxiety disorder not otherwise specified (NOS), depression NOS, body dysmorphic disorder, eating disorder, adjustment disorder, alcohol abuse, cannabis abuse, insomnia, impulse control disorder. ${ }^{\S}$ It includes both major depressive disorder ( $\left.\mathrm{n}=47\right)$ and dysthymia ( $\mathrm{n}=13$ ). 
shown in Table 2. Individuals who were referred out of the clinic after assessment $(n=148)$, compared to patients who were treated $(n=305)$, were more likely to be divorced $\left(\chi^{2}=5.84, \mathrm{df}=1, \mathrm{P}=.05, \eta^{2}=.11\right)$, as well as unemployed $\left(\chi^{2}=11.65, \mathrm{df}=1, \mathrm{P}=.001, \eta^{2}=.16\right)$. These groups did not differ with respect to clinical characteristics [e.g., no differences in terms of presence of PDs, $\chi^{2}=1.78, \mathrm{df}=1, \mathrm{P}=.18, \eta^{2}=.06$, or number of axis I diagnoses, $t(451)=.79, \mathrm{P}=.43, \mathrm{~d}=.07]$. Regarding the final sample, those with and without $\mathrm{PD}$ presence differed only in terms of axis I disturbance. Specifically, individuals with comorbid PDs $(n=114)$ compared to those without axis II comorbidity $(\mathrm{n}=191)$, carried a greater number of axis I diagnoses $[t(303)=4.54, \mathrm{P}<.001, \mathrm{~d}=.52]$. Participants who dropped out $(n=21)$ before completing at least five sessions did not differ from treatment completers on any of the baseline demographic or clinical characteristics [all not significant $(\mathrm{ns})>.05]$.

\section{Presence of axis II comorbidity and magnitude of axis I symptom improvement}

A total of 111 end-treatment measures were missing (36\%) and were imputed using FIML. Some typical reasons for missing data included: premature termination; refusal of participant to complete measures; therapist error; and logistical reasons that preempted administration. Specific data pertaining to these reasons were not assessed for each participant and therefore ns cannot be reported. Participants with imputed data were more likely to have comorbid personality pathology $\left(\chi^{2}=4.38, \mathrm{df}=1, \mathrm{P}=.04, \phi=.12\right)$, and were more likely to be treated for $\operatorname{SAD}\left(\chi^{2}=19.89, \mathrm{df}=1, \mathrm{P}=.001\right.$, $\phi=.26)$. However, given that reasons for missing data were not recorded by all therapists, it cannot be ascertained what constituted this phenomenon.

Results of the 2 (Group: presence $v s$ absence of comorbid PD) $\times 2$ (Time: pre-treatment, end-treatment) repeated measures ANCOVAs revealed that, regardless of co-occurring $\mathrm{PD}$ diagnosis, participants treated for depression $\left[F(1.55)=32.89, \mathrm{P}<.001, \eta^{2}=.38, \mathrm{GAD}, F(1.34)=29.12\right.$,
$\left.\mathrm{P}<.001, \eta^{2}=.46\right]$, panic disorder $[F(1.70)=93.46, \mathrm{P}<.001$, $\left.\eta^{2}=.57\right]$, and SAD $\left[F(1.83)=150.85, \mathrm{P}<.001, \eta^{2}=.65\right]$, but not specific phobias $\left[F(1.14)=5.87, \mathrm{P}=.03, \eta^{2}=.30\right]$, nor OCD $\left[F(1.19)=1.07, \mathrm{P}=.32, \eta^{2}=.05\right]$, demonstrated significant decreases in axis I symptoms (Table 3). There were no significant between-group effects of comorbid PD diagnosis for any of the diagnostic subgroups, with the exception of GAD patients. Among those treated for GAD, individuals with comorbid PDs displayed overall higher axis I symptomatology $\left[F(1.34)=14.44, \mathrm{P}=.001, \eta^{2}=.30\right]$, but this difference was only statistically significant at pretreatment $\left[F(1.34)=11.36, \mathrm{P}=.002, \eta^{2}=.25\right]$. Thus, among GAD patients, those with comorbid PDs had similar levels of post-treatment axis I symptomatology compared to those without PDs $\left[F(1.34)=4.62, \mathrm{P}=.04, \eta^{2}=.12\right]$.

Additionally, there were no group $\times$ time interaction effects for those treated for depression, GAD, panic disorder, SAD, and specific phobias (Table 3). In fact, among these diagnostic groups, both patients with and without PDs showed significant decreases in axis I symptoms. Patients treated for OCD displayed a different pattern of results. Specifically, among OCD patients, those with comorbid PDs showed increases in disorder-specific axis I symptoms, whereas those without personality pathology displayed decreases in axis I symptomatology, resulting in a group $\times$ time interaction effect $[F(1.19)=33.35$, $\left.\mathrm{P}<.001, \eta^{2}=.64\right]$. Post-hoc tests revealed no betweengroup differences in axis I symptomatology at pre-treatment $\left[F(1.19)=.38, \quad \mathrm{P}=.54, \eta^{2}=.02\right]$; however, at post-treatment, those with comorbid PDs had significantly elevated axis I symptomatology compared to those without axis II pathology $\left[F(1.19)=6.27, \mathrm{P}=.007, \eta^{2}=.28\right]$.

\section{Presence of personality disorder comorbidity and treatment outcome classification}

Among those with PDs, the majority of patients treated for depression (68\%), GAD (59\%), panic disorder (55\%) and SAD (66\%), displayed reliable improvement; those without PDs showed generally similar rates of improvement com-

Table 2. Proportion of co-occurring axis II disorders as a function of targeted axis I disorder groups.

\begin{tabular}{|c|c|c|c|c|c|c|c|}
\hline Axes & & $\begin{array}{c}\text { Depression } \\
(n=60)\end{array}$ & $\begin{array}{c}\text { GAD } \\
(n=39)\end{array}$ & $\begin{array}{l}\text { Panic disorder } \\
\qquad(n=75)\end{array}$ & $\begin{array}{c}\text { SAD } \\
(n=87)\end{array}$ & $\begin{array}{c}\text { OCD } \\
(n=24)\end{array}$ & $\begin{array}{l}\text { Phobia } \\
(n=19)\end{array}$ \\
\hline Axis II comorbidity, n (\%) & & $28(46.7)$ & $17(43.6)$ & $22(29.3)$ & $38(43.7)$ & $4(16.7)$ & $5(26.3)$ \\
\hline \multirow{11}{*}{ Axis II diagnoses, n (\%) } & Paranoid PD & $2(3.3)$ & $2(5.1)$ & $4(5.3)$ & $3(34.5)$ & - & $1(5.3)$ \\
\hline & Schizoid PD & - & $1(2.6)$ & - & - & - & - \\
\hline & Schizotypal PD & $2(3.3)$ & - & - & - & - & - \\
\hline & Antisocial PD & - & - & $2(2.7)$ & - & - & - \\
\hline & Borderline PD & $7(11.7)$ & $3(7.7)$ & $7(9.3)$ & $8(9.2)$ & - & $2(10.5)$ \\
\hline & Histrionic PD & $2(3.3)$ & - & - & $1(1.1)$ & - & - \\
\hline & Narcissistic PD & $1(1.7)$ & - & $2(2.7)$ & $1(1.1)$ & - & $1(5.3)$ \\
\hline & Avoidant PD & $5(8.3)$ & $3(7.7)$ & $5(6.7)$ & $6(6.9)$ & - & - \\
\hline & Dependent PD & $4(6.7)$ & $1(2.6)$ & $2(2.7)$ & $3(3.4)$ & - & - \\
\hline & Obsessive-compulsive PD & $9(15.0)$ & $9(23.1)$ & $8(10.7)$ & $8(9.2)$ & $2(8.3)$ & $1(5.3)$ \\
\hline & PD NOS & $5(8.3)$ & $6(15.4)$ & $7(9.3)$ & $8(9.2)$ & $2(8.3)$ & $1(5.3)$ \\
\hline
\end{tabular}

GAD, generalized anxiety disorder; SAD, social anxiety disorder; OCD, obsessive-compulsive disorder; PD, personality disorder; NOS, not otherwise specified. 
pared to their diagnostic counterparts (Table 4). Presence of axis II pathology had a stronger impact on reliable improvement for patients treated for OCD $(25 \%)$ and specific phobias (20\%). Additionally, all axis I groups with co-occurring PDs (with the exception of SAD) showed lower rates of falling below the pre-defined disorder-specific clinical cut-offs compared to those without PDs. Proportions of those meeting criteria for clinical recovery (reliably improved and falling below cut-off points) as a function of PD presence were next examined. After controlling for covariates, results of the multivariate logistic regression analyses indicated that only patients treated for GAD evidenced a significant relationship between treatment outcome and PD status. Specifically, GAD patients with personality pathology, compared to those without axis II comorbidity, were approximately one twentieth as likely to be classified as recovered (adjusted $\mathrm{OR}=.05$; 95\% CI=.01-.41; Table 4). Due to the relatively low sample sizes within each diagnostic group, further analyses could not be conducted examining which particular PDs or clusters of PDs contributed to worse treatment outcome.

\section{Quantity of personality disorders and magnitude of axis I symptom improvement}

Associations between number of axis II diagnoses and magnitude of symptom reduction was examined among the subgroups of individuals with personality pathology $(n=114)$. After controlling for covariates, results revealed that number of axis II diagnoses was not associated with magnitude of axis I symptom change for any of the diagnostic subgroups $(\beta \mathrm{s}=.10-.27, t \mathrm{~s}=.97-2.20, p \mathrm{~s}=.03-.63$, $\left.s r^{2}=.01-.05\right)$. Analyses were not conducted within OCD $(n=4)$ and specific phobia $(n=5)$ patients, given the insufficient numbers of individuals with PDs.

\section{Personality disorder cluster and magnitude of axis I symptom improvement}

Among those with personality pathology, PD cluster was not associated with magnitude of axis I symptom change for any of the diagnostic subgroups (cluster A: $\beta \mathrm{s}=.13-.39, t \mathrm{~s}=.63-1.24, p \mathrm{~s}=.25-.53, s r^{2}=.01-.10$; cluster $\mathrm{B}=\beta \mathrm{s}=.03-.59, t \mathrm{~s}=.27-1.24, p \mathrm{~s}=.10-.79, s r^{2}=<.001-.10$; cluster $\mathrm{C}: \beta \mathrm{s}=.10-.62, t \mathrm{~s}=.77-2.49, p \mathrm{~s}=.03-.45, s r^{2}: .01-.12 ; \mathrm{PD}$ NOS: $\left.\beta \mathrm{s}=.05-.63, t \mathrm{~s}=.28-2.32, p \mathrm{~s}=.05-.78, s r^{2}=.001-.22\right)$. Analyses were not conducted within OCD $(n=4)$ and specific phobia $(n=5)$ patients, given the insufficient numbers of individuals with PDs.

\section{Discussion}

The present study examined the effects of axis II PD comorbidity on CBT treatment outcome for mood and

Table 3. Effects of axis II comorbidity on magnitude of axis I symptom change ( $n=305)$.

\begin{tabular}{|c|c|c|c|c|c|c|c|c|c|c|c|c|c|}
\hline \multirow[t]{2}{*}{ Group } & \multirow[t]{2}{*}{$\mathbf{N}$} & \multicolumn{2}{|c|}{$\begin{array}{c}\text { Pre-treatment } \\
\text { score }\end{array}$} & \multicolumn{2}{|c|}{$\begin{array}{c}\text { End-treatment } \\
\text { score }\end{array}$} & \multirow[t]{2}{*}{$\Delta$} & \multirow[t]{2}{*}{$\eta^{2}$} & \multirow[t]{2}{*}{ Time $(F)^{\circ}$} & \multirow[t]{2}{*}{$\eta^{2}$} & \multirow[t]{2}{*}{$\operatorname{Group}(F)^{\circ}$} & \multirow[t]{2}{*}{$\eta^{2}$} & \multirow[t]{2}{*}{$\begin{array}{c}\text { Time } \times \text { group } \\
(F)^{\circ}\end{array}$} & \multirow[t]{2}{*}{$\eta^{2}$} \\
\hline & & $\mathbf{M}$ & SE & $\mathbf{M}$ & SE & & & & & & & & \\
\hline \multicolumn{14}{|l|}{ Depression patients ${ }^{\#}$} \\
\hline No comorbid PD & 32 & 21.67 & 2.14 & 13.79 & 2.22 & $7.88^{*}$ & .25 & - & - & - & - & - & - \\
\hline Comorbid PD & 28 & 21.35 & 2.22 & 14.06 & 2.30 & $7.30^{*}$ & .21 & $32.89 *$ & .38 & .01 & .001 & .05 & .001 \\
\hline \multicolumn{14}{|l|}{ GAD patients } \\
\hline No comorbid PD & 22 & 61.53 & 2.06 & 48.77 & 2.66 & $12.77 *$ & .29 & - & - & - & - & - & - \\
\hline Comorbid PD & 17 & 72.19 & 2.35 & 57.55 & 3.04 & $14.64 *$ & .30 & $29.12 *$ & .46 & $14.44 *$ & .30 & .13 & .01 \\
\hline \multicolumn{14}{|c|}{ Panic disorder patients } \\
\hline No comorbid PD & 53 & 41.12 & 3.50 & 22.52 & 2.38 & $18.61 *$ & .48 & - & - & - & - & - & - \\
\hline Comorbid PD & 22 & 49.31 & 5.68 & 26.91 & 3.87 & $22.40 *$ & .33 & $93.46^{*}$ & .57 & 1.31 & .02 & .67 & .01 \\
\hline \multicolumn{14}{|l|}{ SAD patients } \\
\hline No comorbid PD & 50 & 49.51 & 2.61 & 27.34 & 2.31 & $22.17 *$ & .43 & - & - & - & - & - & - \\
\hline Comorbid PD & 38 & 55.00 & 2.98 & 25.91 & 2.64 & $29.08 *$ & .50 & $150.85^{*}$ & .65 & .42 & .01 & 2.51 & .03 \\
\hline \multicolumn{14}{|l|}{ OCD patients } \\
\hline No comorbid PD & 20 & 21.97 & 2.22 & 13.71 & 1.96 & $8.26^{*}$ & .80 & - & - & - & - & - & - \\
\hline Comorbid PD & 4 & 18.40 & 5.21 & 24.24 & 4.60 & 5.84 & .27 & 1.07 & .05 & .43 & .02 & $33.35^{*}$ & .64 \\
\hline \multicolumn{14}{|l|}{ Phobia patients } \\
\hline No comorbid PD & 14 & 13.30 & 2.24 & 5.33 & 1.10 & $7.97 *$ & .52 & - & - & - & - & - & - \\
\hline Comorbid PD & 5 & 6.80 & 4.41 & 4.20 & 2.17 & 2.60 & .01 & 5.87 & .30 & 6.27 & .31 & 1.68 & .11 \\
\hline
\end{tabular}

M, mean; SE, standard error of the mean; PD, personality disorder; GAD, generalized anxiety disorder; SAD, social anxiety disorder; OCD, obsessive-compulsive disorder. Means represent estimated marginal means. ${ }^{*} \mathrm{P}<.008$. Depression, GAD, panic disorder, SAD, OCD, and specific phobia symptoms assessed with the Beck depression inventory-II (BDI-II; Beck et al., 1996), Penn State worry questionnaire (PSWQ; Meyer et al., 1990), panic appraisal inventory (PAI-1; Telch et al., 1989), appraisal of social concerns (ASC; Telch et al., 2004), Yale-Brown obsessivecompulsive scale (Y-BOCS; Goodman, Price, Rasmussen, Mazure, Delgado, et al., 1989; Goodman, Price, Rasmussen, Mazure, Fleischmann, et al., 1989), and Beck anxiety inventory (BAI; Beck et al., 1988), respectively. Axis I and axis II psychopathology were assessed via the structured clinical interview axes I (SCID-I; First et al., 1996) and axis II (SCID-II; First et al., 1997) for the diagnostic and statistical manual of mental disorders-fourth edition (DSM-IV). ${ }^{\circ}$ Model adjusted for age, number of axis I diagnoses, and number of treatment sessions. ${ }^{\# I t ~ i n c l u d e s ~ m a j o r ~}$ depressive disorder, single and recurrent episodes combined $(n=47)$ and dysthymia $(n=13)$. 
anxiety disorders among adult outpatients treated by trainee therapists within a university training clinic. Results using end-treatment measures indicated that the majority of diagnostic groups (i.e., those treated for depression, GAD, panic disorder, $\mathrm{SAD}$, and specific phobias) did not evidence differential treatment effects with respect to the effect of PD presence on magnitude of disorder-specific axis I symptom reduction. Furthermore, improvements among these groups were statistically significant for those with and without PDs and effect sizes were medium to large. These findings, produced by student trainees, are in line with findings from other studies showing similar reductions in axis I symptomatology among those with and without PDs (Black, Wesner, Gabel, Bowers, \& Monahan, 1994; Dreessen, Arntz, Luttels, \& Sallaerts, 1994; Dreessen, Hoekstra, \& Arntz, 1997; Sanderson, Beck, \& McGinn, 1994; van den Hout, Brouwers, \& Oomen, 2006).

Patients treated for OCD, on the other hand, showed a different pattern of results. Specifically, those with comorbid PDs had significantly elevated axis I symptomatology at post-treatment compared to those without axis II pathology. In fact, contrary to their non-PD counterparts, OCD patients with axis II pathology did not demonstrate significant reductions in axis I symptoms. These results, although tentative (given the low sample size in this diagnostic group), are in concert with other studies that have shown PDs to be predictive of poorer treatment outcome among OCD patients (Cavedini, Erzegovesi, Ronchi, \& Bellodi, 1997; Fals-Stewart \& Lucente, 1993).

When exploring the effects of co-occurring PDs on treatment response using reliable change and a priori cutoff values (i.e., recovered, non-recovered), PD presence exerted deleterious effects on treatment outcome among patients treated for GAD. Specifically, among this diagnostic subgroup, those with PDs were approximately one twentieth as likely as patients without PD presence to be classified as clinically recovered. These findings are in line with a study by Massion and colleagues (2002), which investigated effects of PDs on a variety of anxiety disorders and found that PDs negatively impacted remission rates for GAD patients but not for panic disorder patients. Finally, among those with PDs, neither PD quantity nor PD cluster moderated treatment response for any diagnostic subgroup.

The theoretical implications of this general finding of a lack of CBT differential effects with respect to axis II personality disorder comorbidity upon the magnitude of axis I disorder symptom reduction deserve some comment. Indeed, despite the presumption in traditional psy-

Table 4. Association between presence of axis II comorbidity and cognitive-behavioral therapy treatment outcome classification $(\mathbf{n}=\mathbf{3 0 5})$.

\begin{tabular}{|c|c|c|c|c|c|c|c|c|c|c|}
\hline Group & $\begin{array}{c}\text { Reliably } \\
\text { improved } \\
(\%)\end{array}$ & $\begin{array}{c}\text { Below } \\
\text { clinical } \\
\text { cut-off } \\
\text { score }(\%)\end{array}$ & n & & Recovered & $\%$ & $\begin{array}{c}\text { Unadjusted } \\
\text { OR }\end{array}$ & $95 \%$ CI & $\begin{array}{l}\text { Multivariate } \\
\text { adjusted } \mathrm{OR}^{\circ}\end{array}$ & $95 \%$ CI \\
\hline \multicolumn{11}{|l|}{ Depression patients ${ }^{\#}$} \\
\hline No comorbid PD (referent) & 53.3 & 60.0 & 13 & 40.6 & 19 & 59.4 & & & & \\
\hline Comorbid PD & 67.9 & 50.0 & 11 & 39.3 & 17 & 60.7 & .95 & $.34-2.66$ & 1.07 & $.34-3.39$ \\
\hline \multicolumn{11}{|l|}{ GAD patients } \\
\hline No comorbid PD (referent) & 77.3 & 72.7 & 14 & 63.6 & 8 & 36.4 & & & & \\
\hline Comorbid PD & 58.8 & 23.5 & 4 & 23.5 & 13 & 76.5 & .18 & $.04-.73$ & $.05^{*}$ & $.01-.41$ \\
\hline \multicolumn{11}{|l|}{ Panic disorder patients } \\
\hline No comorbid PD (referent) & 39.6 & 71.7 & 14 & 26.4 & 39 & 73.6 & & & & \\
\hline Comorbid PD & 54.5 & 59.1 & 8 & 36.4 & 14 & 63.6 & 1.59 & $.55-4.60$ & 3.34 & $.87-12.79$ \\
\hline \multicolumn{11}{|l|}{ SAD patients } \\
\hline No comorbid PD (referent) & 42.9 & 77.6 & 20 & 40.0 & 30 & 60.0 & & & & \\
\hline Comorbid PD & 65.8 & 84.2 & 10 & 26.3 & 28 & 73.7 & .54 & $.21-1.34$ & .32 & $.11-.94$ \\
\hline \multicolumn{11}{|l|}{ OCD patients } \\
\hline No comorbid PD (referent) & 85.0 & 75.0 & 11 & 55.0 & 9 & 45.0 & & & & \\
\hline Comorbid PD & 25.0 & 25.0 & 1 & 25.0 & 3 & 75.0 & .27 & $.02-3.09$ & .06 & $.01-5.56$ \\
\hline \multicolumn{11}{|l|}{ Phobia patients } \\
\hline No comorbid PD (referent) & 28.6 & 71.4 & 8 & 57.1 & 6 & 42.9 & & & & \\
\hline Comorbid PD & 20.0 & 40.0 & 1 & 20.0 & 4 & 80.0 & .19 & $.02-2.14$ & .07 & $.01-21.87$ \\
\hline
\end{tabular}

$\mathrm{OR}$, odds ratio; $\mathrm{CI}$, confidence interval; $\mathrm{PD}$, personality disorder; $\mathrm{GAD}$, generalized anxiety disorder; $\mathrm{SAD}$, social anxiety disorder; $\mathrm{OCD}$, obsessive-compulsive disorder. ${ }^{*} \mathrm{P}<.008$. Depression, GAD, panic disorder, SAD, OCD, and specific phobia symptoms assessed with the Beck depression inventory-II (BDI-II; Beck et al., 1996), Penn State worry questionnaire (PSWQ; Meyer et al., 1990), panic appraisal inventory (PAI-1; Telch et al., 1989), appraisal of social concerns (ASC; Telch et al., 2004), Yale-Brown obsessive-compulsive scale (Y-BOCS; Goodman, Price, Rasmussen, Mazure, Delgado, et al., 1989; Goodman, Price, Rasmussen, Mazure, Fleischmann, et al., 1989), and Beck anxiety inventory (BAI; Beck et al., 1988), respectively. Axis I and axis II psychopathology were assessed via the structured clinical interview axes I (SCID-I; First et al., 1996) and axis II (SCID-II; First et al., 1997) for the diagnostic and statistical manual of mental disorders-fourth edition (DSM-IV). ${ }^{\circ}$ Model adjusted for age, number of axis I diagnoses, number of treatment sessions, and pre-treatment symptom severity score. ${ }^{\# I t}$ includes both major depressive disorder $(\mathrm{n}=47)$ and dysthymia $(\mathrm{n}=13)$. 
chotherapy that negative personality traits and axis II psychopathology should adversely affect axis I treatment outcomes (e.g., Zinbarg, Uliaszek, \& Adler, 2008), in our study as well as in a recent meta-analysis (Olatunji, Cisler, \& Tolin, 2010) depression and anxiety disorder treatment effects were not diminished by the presence of comorbid personality disorders. CBT assumes that targets for intervention can be specific to particular symptoms or DSM disorders, regardless of axes I or II comorbidity. The DSM-5 likewise has eliminated axis II and now groups personality disorders and formerly axis I disorders together as a way of addressing comorbidity (e.g., Links \& Eynan, 2013). What about the discrepant finding that CBT for GAD in this training clinic setting did appear to be negatively influenced by comorbid personality disorders? One reason is that GAD clients attain a lower percentage of clinically significant change in response to treatment than that for other anxiety disorders (Newman \& Borkovec, 2002). Second, another assumption of personality and psychotherapy has been that personality disorders impair the formation of the therapeutic alliance and/or can lead to ruptures in an otherwise good working alliance (e.g., Martino, Menchetti, Pozzi, \& Berardi, 2012; Zinbarg et al. 2008). In a recent review of GAD, its etiology, and treatment, Newman, Llera, Erickson, Przeworski, and Castonguay (2013) summarized the predictive validity of interpersonal problems linked to personality traits that can contribute to poorer outcomes in CBT for GAD. We did not routinely measure the therapeutic alliance in our training clinic but we now are recommending the Inventory of Interpersonal Problems (IIP, Horowitz, Alden, Wiggins, \& Pincus, 2000) as a supplemental measure (Hawkins \& Meier, 2015), which would permit future research studies to explore the contribution of negative personality attributes that may impact the working alliance and thus limit treatment effectiveness for anxious and/or depressed clients with comorbid personality disorders.

\section{Limitations and strengths of the study}

There are a number of limitations of our study that warrant mention.

First, this study investigated the potential impact of PDs on axis I treatment outcome by grouping all personality disorders together (thereby serving as a binarily coded between-group variable). Similar to other studies, we were unable to statistically examine the predictive effects of individual PD diagnoses on axis I symptom reduction due to their insufficient frequency. Therefore, it remains unclear whether there was a particular PD or pattern of PDs either within or across PD clusters that contributed to the observed effects.

Second, although personality pathology was reliably assessed using the SCID-II, which is capable of measuring level of axis II pathology (i.e., via a symptom count), only the presence of each PD (measured categorically as yes/no) was recorded in the archival database. This coding technique pre-empted the dimensional analysis of axis II pathology, which may offer enhanced validity by decreasing diagnostic overlap of PDs, while also enabling one to explore personality features along a continuum (Costa \& McCrae, 1992).

Third, the CPTC database contains no data regarding current psychiatric medication use. This is an important factor given that several studies have shown that psychotropic medications (particularly selective serotonin reuptake inhibitors) can reduce certain facets of personality pathology, which in turn has the potential to moderate treatment outcome (Aberg-Wistedt, Agren, Ekselius, Bengtson, \& Akerblad, 2000; Black et al., 1994; Fava, Grandi, Zielezny, Canestrari, \& Morphy, 1994; Reich, 2003; Tyrer, Seivewright, Ferguson, Murphy, \& Johnson, 1993).

A fourth limitation is that - for patients with missing end-treatment data - we have no indication whether these patients successfully completed treatment, as this designation was not recorded within the CPTC database. As such, we acknowledge that this may create a selection bias that can affect generalization of our results. However, we did attempt to determine whether premature dropout (defined as discontinuing treatment before completing at least five sessions) may have differentially affected the results. In fact, findings showed that participants who dropped out before completing at least five sessions did not differ from treatment completers on any baseline demographic or clinical characteristic. Additionally, we used full information maximum likelihood (FIML) estimation to address missing data. FIML is considered a state-of-the art approach (Schafer \& Graham, 2002) and has been shown to produce more accurate parameter estimates than either list-wise deletion or LOCF (Enders, 2001; Enders \& Bandalos, 2001; Schafer \& Graham, 2002). Additionally, Little and Rubin (2002) and Schafer (1997) have both suggested that data estimation methods using FIML can reliably be used when up to $90 \%$ of the data are missing for a particular variable.

A fifth limitation was that all diagnoses were determined using standardized structured psychiatric interviews administered by trainee therapists under close supervision by a licensed psychologist. The CPTC database, unfortunately, does not contain reliability data pertaining to DSM diagnoses, which is a limitation common to many studies utilizing training clinic data (Forand et al., 2011; Persons et al., 2006; Westbrook \& Kirk, 2005).

A final limitation pertains to the generalization of these results. Given that these data were based upon CBT treatment outcome delivered by graduate students within a university training clinic, findings may not generalize to typical outpatients for a variety of reasons. Given the nature of the training clinic, patients were referred elsewhere if they were suicidal or if they presented with substance dependence. This may have excluded patients with more severe levels of axis I pathology, as well as individuals with 
more severe comorbid axis II symptomatology. Additionally, more severe anxiety disorders such as PTSD were not present in sufficient numbers to be included in analyses, and therefore our sample of anxiety disorder patients may represent a more milder range of axis I pathology.

Limitations notwithstanding, there were several strengths of the present investigation. First, assessment of mood and anxiety symptoms was reliably conducted using gold-standard assessment instruments.

Second, this study included a wide variety of mood and anxiety diagnostic groups, in an attempt to enhance the generalizability of the results.

Third, this investigation employed rigorous statistical procedures (intent-to-treat analyses via multiple imputation, statistical control for covariates, as well as pre-treatment levels of symptomatology) in an attempt to redress limitations of prior studies assessing the impact of personality pathology on axis I treatment response.

Finally, this study used several indices of treatment response - such as magnitude of symptom change, reliable change, and clinical significance - to reliably and comprehensively assess whether PD comorbidity impacted treatment outcome classification.

\section{Conclusions}

In conclusion, these findings suggest that, in most instances (with the exception of GAD and OCD patients), individuals with PDs treated by graduate student trainees within a university training clinic experienced notable axis I symptom improvement with short-term CBT, comparable to those without co-occurring PDs. Thus the patients treated by student trainees within the CPTC had a good likelihood of experiencing improvement in their symptoms, irrespective of PD comorbidity. However, it should be acknowledged that approximately two-thirds of those patients still experienced residual symptoms at endtreatment. Thus, additional treatment (either adjunctive, or as an extension of the initial short-term CBT course) may be necessary for patients with more severe axis I and/or axis II pathology. Additionally, because this study only examined the acute effects of CBT treatment, susceptibility of relapse among improved PD clients treated by trainees remains unknown.

\section{References}

Aberg-Wistedt, A., Agren, H., Ekselius, L., Bengtson, F., \& Akerblad, A.C. (2000). Sertraline versus paroxetine in major depression: clinical outcome after six months of continuous therapy. Journal of Clinical Psychopharmacology, 20(6), 645-652.

American Psychiatric Association (1994). Diagnostic and statistical manual of mental disorders (4th ed.). Washington, DC: American Psychiatric Association.

Barlow, D.H. (2008). Clinical handbook of psychological dis- orders: a step-by-step treatment manual (4th ed.). New York, NY: Guilford.

Beck, A.T., Epstein, N., Brown, G., \& Steer, R.A. (1988). An inventory for measuring clinical anxiety: psychometric properties. Journal of Consulting \& Clinical Psychology, 56(6), 893-897.

Beck, A.T., \& Steer, R.A. (1990). Manual for the Beck anxiety inventory. San Antonio, TX: The Psychological Corporation.

Beck, A.T., Steer, R.A., \& Brown, G.K. (1996). Beck depression inventory manual (2nd ed.). San Antonio, TX: The Psychological Corporation.

Beck, J.G., Stanley, M.A., \& Zebb, B.J. (1995). Psychometric properties of the Penn State worry questionnaire in older adults. Journal of Clinical Geropsychology, 1, 33-42.

Black, D.W., Wesner, R.B., Gabel, J., Bowers, W., \& Monahan, P. (1994). Predictors of short-term treatment response in 66 patients with panic disorder. Journal of Affective Disorders, 30(4), 233-241.

Cavedini, P., Erzegovesi, S., Ronchi, P., \& Bellodi, L. (1997). Predictive value of obsessive-compulsive personality disorder in antiobsessional pharmacological treatment. European Neuropsychopharmacology, 7(1), 45-49.

Cho, Y., Smits, J.A.J., Powers, M.B., \& Telch, M.J. (2007). Do changes in panic appraisal predict improvement in clinical status following cognitive-behavioral treatment of panic disorder? Cognitive Therapy and Research, 31(5), 695-707.

Costa, P.T., \& McCrae, R.R. (1992). The five-factor model of personality and its relevance to personality disorders. Journal of Personality Disorders, 6(4), 343-359.

Dreessen, L., \& Arntz, A. (1998). The impact of personality disorders on treatment outcome of anxiety disorders: best-evidence synthesis. Behaviour Research and Therapy, 36(5), 483-504

Dreessen, L., Arntz, A., Luttels, C., \& Sallaerts, S. (1994). Personality disorders do not influence the results of cognitive behavior therapies for anxiety disorders. Comprehensive Psychiatry, 35(4), 265-274.

Dreessen, L., Hoekstra, R., \& Arntz, A. (1997). Personality disorders do not influence the results of cognitive and behavior therapy for obsessive compulsive disorder. Journal of Anxiety Disorders, 11(5), 503-521.

Enders, C.K. (2001). The performance of the full information maximum likelihood estimator in multiple regression models with missing data. Educational and Psychological Measurement, 61(5), 713.

Enders, C.K., \& Bandalos, D.L. (2001). The relative performance of full information maximum likelihood estimation for missing data in structural equation models. Structural Equation Modeling, 8(3), 430-457.

Fals-Stewart, W., \& Lucente, S. (1993). An MCMI cluster typology of obsessive-compulsives: a measure of personality characteristics and its relationship to treatment participation, compliance and outcome in behavior therapy. Journal of Psychiatric Research, 27(2), 139-154.

Fava, G.A., Grandi, S., Zielezny, M., Canestrari, R., \& Morphy, M.A. (1994). Cognitive behavioral treatment of residual symptoms in primary major depressive disorder. American Journal of Psychiatry, 151(9), 1295-1299.

Feske, U., \& De Beurs, E. (1997). The panic appraisal inventory: psychometric properties. Behaviour Research and Therapy, 35(9), 875-882.

First, M.B., Gibbon, M., Spitzer, R.L., Williams, J.B.W., \& Benjamin, L.S. (1997). User's guide for the structured clinical 
interview for DSM-IV axis II personality disorders (SCIDII). Washington, DC: American Psychiatric Press.

First, M.B., Spitzer, R.L., Gibbon, M., \& Williams, J.B.W. (1996). Structured clinical interview for DSM-IV axis I disorders - patient edition (SCID-I/P), version 2.0. New York, NY: New York State Psychiatric Institute, Biometrics Research Department.

Forand, N.R., Evans, S., Haglin, D., \& Fishman, B. (2011). Cognitive behavioral therapy in practice: treatment delivered by trainees at an outpatient clinic is clinically effective. Behavior Therapy, 42, 612-623.

Friborg, O., Martinussen, M., Kaiser, S., Overgard, K.T., \& Rosenvinge, J.H. (2013). Comorbidity of personality disorders in anxiety disorders: a meta-analysis of 30 years of research. Journal of Affective Disorders, 145, 143-155.

Gibbons, C.J., Fournier, J.C., Stirman, S.W., DeRubeis, R.J., Crits-Christoph, P., \& Beck, A.T. (2010). The clinical effectiveness of cognitive therapy for depression in an outpatient clinic. Journal of Affective Disorders, 125(1-3), 169-176. doi: 10.1016/j.jad.2009.12.030

Goodman, W.K., Price, L.H., Rasmussen, S.A., Mazure, C., Delgado, P., Heninger, G.R., \& Charney, D.S. (1989). The YaleBrown Obsessive Compulsive Scale: II. Validity. Archives of General Psychiatry, 46(11), 1012-1016.

Goodman, W.K., Price, L.H., Rasmussen, S.A., Mazure, C., Fleischmann, R.L., Hill, C.L.,..., Charney, D.S. (1989). The YaleBrown obsessive compulsive scale: I. Development, use, and reliability. Archives of General Psychiatry, 46(11), 1006-1011.

Grilo, C.M., Sanislow, C.A., Shea, M.T., Skodol, A.E., Stout, R.L., Gunderson, J.G.,..., Zanarini, M.C. (2005). Two-year prospective naturalistic study of remission from major depressive disorder as a function of personality disorder comorbidity. Journal of Consulting and Clinical Psychology, 73(1), 78-85.

Hawkins, R.C. II, \& Meier, S.T. (2015). Psychotherapeutic theories of change and measurement: an integrative model. Journal of Unified Psychotherapy and Clinical Science, 3(1), 80-119.

Horowitz, L.M., Alden, L.E., Wiggins, J.S., \& Pincus, A.L. (2000). Inventory of interpersonal problems manual. Odessa, FL: The Psychological Corporation.

Jacobson, N.S., \& Truax, P. (1991). Clinical significance: a statistical approach to defining meaningful change in psychotherapy research. Journal of Consulting and Clinical Psychology, 59(1), 12-19.

Kelly, B.D., Nur, U.A., Tyrer, P., \& Casey, P. (2009). Impact of severity of personlaity disorder on the outcome of depression. European Psychiatry, 24, 322-326.

Links, P.S. \& Eynan, R. (2013). The relationship between personality disorders and axis I psychopathology: deconstructing comorbidity. Annual Review of Clinical Psychology, 9, 529-554.

Little, R.J.A., \& Rubin, D.B. (2002). Statistical analysis with missing data (2nd ed.). Hoboken, NJ: Wiley-Interscience.

Lucas, R., \& Telch, M. (1993). Group versus individual treatment of social phobia. Paper presented at the the Annual Meeting of the Association for the Advancement of Behavior Therapy, Atlanta, GA.

Martino, F., Menchetti, M., Pozzi, E., \& Berardi, D. (2012). Predictors of dropout among personality disorders in a specialist outpatients psychosocial treatment: a preliminary study. Psychiatry and Clinical Neurosciences, 66, 180-186.

Massion, A.O., Dyck, I.R., Shea, M.T., Phillips, K.A., Warshaw,
M.G., \& Keller, M.B. (2002). Personality disorders and time to remission in generalized anxiety disorder, social phobia, and panic disorder. Archives of General Psychiatry, 59(5), 434-440.

Meyer, T.J., Miller, M.L., Metzger, R.L., \& Borkovec, T.D. (1990). Development and validation of the Penn State worry questionnaire. Behaviour Research and Therapy, 28(6), 487495. doi: 10.1016/0005-7967(90)90135-6

Mulder, R.T. (2002). Personality pathology and treatment outcome in major depression: a review. American Journal of Psychiatry, 159(3), 359-371.

Newman, M.G., \& Borkovec, T.D. (2002). Cognitive-behavioral therapy for worry and generalized anxiety disorder. In: G. Sinos (Ed.) Cognitive behaviour therapy: a guide for the practicing clinician (pp. 150-172). New York, NY: Taylor \& Francis.

Newman, M.G., Llera, S.J., Erickson, T.M., Przeworski, A., \& Castonguay, L.G. (2013). Worry and generalized anxiety disorder: a review and theoretical synthesis of evidence on nature, etiology, mechanisms, and treatment. Annual Reviews of Clinical Psychology, 9, 275-297.

Newton-Howes, G., Tyrer, P., \& Johnson, T. (2006). Personality disorder and the outcome of depression: meta-analysis of published studies. The British Journal of Psychiatry, 188(1), 13-20.

Olatunji, B.O., Cisler, J.M., \& Tolin, D.F. (2010). A meta-analysis of the influence of comorbidity on treatment outcome in the anxiety disorders. Clinical Psychology Review, 30, 642-654.

O'Leary, D., \& Costello, F. (2001). Personality and outcome in depression: an 18-month prospective follow-up study. Journal of Affective Disorders, 63, 67-78.

Persons, J.B., Roberts, N.A., Zalecki, C.A., \& Brechwald, W.A. (2006). Naturalistic outcome of case formulation-driven cognitive-behavior therapy for anxious depressed outpatients. Behaviour Research and Therapy, 44(7), 1041-1051. doi: $10.1016 /$ j.brat.2005.08.005

Reich, J.H. (2003). The effect of axis II disorders on the outcome of treatment of anxiety and unipolar depressive disorders: a review. Journal of Personality Disorders, 17(5), 387-405.

Reich, J.H., \& Green, A.I. (1991). Effect of personality disorders on outcome of treatment. Journal of Nervous and Mental Disease, 179, 74-82.

Reich, J.H., \& Vasile, R.G. (1993). Effect of personality disorders on the treatment outcome of Axis I conditions: an update. Journal of Nervous and Mental Disease, 181, 475-484.

Sanderson, W.C., Beck, A.T., \& McGinn, L.K. (1994). Cognitive therapy for generalized anxiety disorder: significance of comorbid personality disorders. Journal of Cognitive Psychotherapy, 8(1), 13-18.

Schafer, J.L. (1997). Analysis of incomplete multivariate data. Boca Raton, FL: Chapman \& Hall/CRC.

Schafer, J.L., \& Graham, J.W. (2002). Missing data: our view of the state of the art. Psychological Methods, 7(2), 147-177.

Schultz, L.T., Heimberg, R.G., Rodebaugh, T.L., Schneier, F.R., Liebowitz, M.R., \& Telch, M.J. (2006). The appraisal of social concerns scale: psychometric validation with a clinical sample of patients with social anxiety disorder. Behavior Therapy, 37(4), 392-405.

Shea, M.T., Pilkonis, P.A., Beckham, E., Collins, J.F., Elkin, E., Sotsky, S.M., \& Docherty, J.P. (1990). Personality disorders and treatment outcome in the NIMH Treatment of Depression Collaborative Research Program. American Journal of Psychiatry, 147, 711-718.

Shea, M.T., Widiger, T.A., \& Klein, M.H. (1992). Comorbidity of personality disorders and depression: implications for 
treatment. Journal of Consulting and Clinical Psychology, 60 (6), 857-868

Skodol, A.E., Geier, T., Grant, B.F., \& Hasin, D.S. (2014). Personality disorders and the persistence of anxiety disorders in a nationally representative sample. Depression and Anxiety, 31, 721-728.

Telch, M.J., Brouillard, M., Telch, C.F., Agras, W.S., \& Taylor, C.B. (1989). Role of cognitive appraisal in panic-related avoidance. Behaviour Research and Therapy, 27(4), 373383. doi: 10.1016/0005-7967(89)90007-7

Telch, M.J., Lucas, R.A., Smits, J.A.J., Powers, M.B., Heimberg, R., \& Hart, T. (2004). Appraisal of social concerns: a cognitive assessment instrument for social phobia. Depression and Anxiety, 19(4), 217-224.

Tyrer, P., Seivewright, N., Ferguson, B., Murphy, S., \& Johnson, A. (1993). The Nottingham study of neurotic disorder: effect of personality status on response to drug treatment, cognitive therapy and self-help over two years. The British Journal of Psychiatry, 162(2), 219-226. van den Hout, M., Brouwers, C., \& Oomen, J. (2006). Clinically diagnosed axis II co-morbidity and the short term outcome of CBT for axis I disorders. Clinical Psychology \& Psychotherapy, 13(1), 56-63.

van Velzen, C.J.M., \& Emmelkamp, P.M.G. (1996). The assessment of personality disorders: implications for cognitive and behavior therapy. Behaviour Research and Therapy, 34(8), 655-668.

Weertman, A., Arntz, A., Schouten, E., \& Dreesen, L. (2005). Influences of beliefs and personality disorders on treatment outcome in anxiety patients. Journal of Consulting and Clinical Psychology, 73(5), 936-944.

Westbrook, D., \& Kirk, J. (2005). The clinical effectiveness of cognitive behaviour therapy: outcome for a large sample of adults treated in routine practice. Behaviour Research and Therapy, 43(10), 1243-1261.

Zinbarg, R.E., Uliaszek, A.A., \& Adler, J.M. (2008). The role of personality in psychotherapy for anxiety and depression. Journal of Personality, 76(6), 1649-1688. 